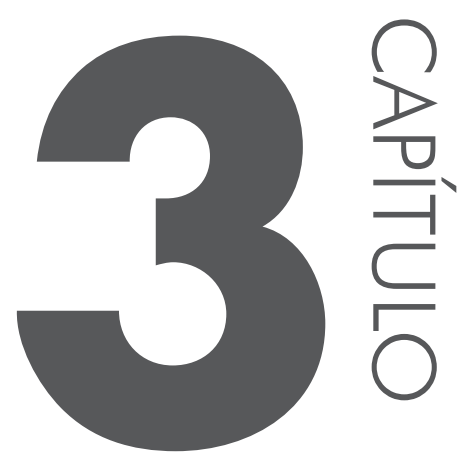

\title{
O Centro de Estudos do Deserto
}

\section{Samuel Rogrigues Aço}

Njambasana, fevereiro de 2014

Trata-se de uma associação de caráter científico, apartidária, laica, sem fins lucrativos, não governamental, baseada no caráter voluntário dos seus membros, com autonomia jurídica, administrativa e financeira, que tem como objetivo contribuir para o estudo das regiões áridas e semiáridas de Angola, em particular do deserto do Namibe, de forma a aprofundar o conhecimento das suas características físicas, ambientais e sociais, utilizando a investigação científica, a educação e o ensino profissional, a assessoria técnica e consultoria como vias para a proteção do ecossistema e para o desenvolvimento sustentável e endógeno dessas regiões. Assim, o CE.DO:

- estabelece e apoia programas de pesquisa sobre as regiões áridas e procede à edição de publicações, realização de debates, palestras, seminários, simpósios etc.;

- contribui para o estudo integral do ambiente físico e social das regiões desérticas e semidesérticas de Angola, de forma a desenvolver na sociedade angolana a compreensão das suas especificidades e a necessidade de serem respeitadas essas características;

- empreende ações para apoio ao desenvolvimento sustentável e endógeno dessas regiões;

- desenvolve ações educativas em todos os níveis e executa ações específicas de formação e treinamento nos domínios técnico, ambiental, turístico, sanitário e de gestão orientada de recursos humanos. 


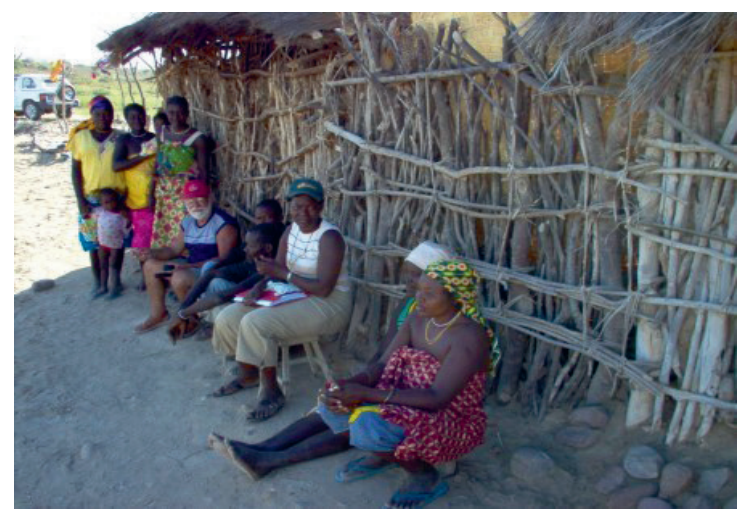

Figura 3.1 - Conversando com moradoras do Kuroca. Fonte: acervo CE.DO.

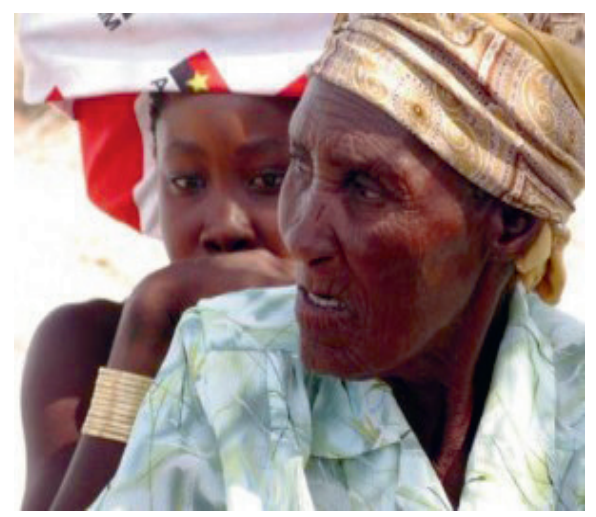

Figura 3.2 - Senhoras do Kuroca. Fonte: acervo CE.DO.

\section{Formação e atividades do Centro de Estudos do Deserto - 2004-2014}

1. O Centro de Estudos do Deserto constitui-se como Associação da Sociedade Civil na sequência da pesquisa realizada por um investigador individual, a partir do ano 2000, sobre os “comerciantes do deserto" e a aplicação, em 2004, do "Questionário Integrado para Medir o Capital Social”, este realizado com a participação de docentes e estudantes da Faculdade de Letras e Ciências Sociais da Universidade Agostinho Neto e em colaboração com o Instituto de Ciências Sociais da Universidade de Lisboa.

2. No decorrer destas atividades, verificou-se a necessidade de criar um suporte às pesquisas científicas nas áreas das ciências sociais tão necessárias ao desenvolvimento da região. 
3. Como corolário da atividade científica, torna-se clara a ideia de usufruir das capacidades das pessoas que se deslocassem ao terreno de pesquisa para colaborar com o desenvolvimento local.

4. Obtém-se, assim, o patrocínio do Governo Provincial do Namibe e da empresa Toyota de Angola para construção de um Centro de Formação em Artes e Ofícios com vista a colmatar a carência total de formações profissionais na região.

O Centro de Estudos do Deserto constituiu-se no Dia da África de 2007, em 25 de maio, como uma associação não governamental, laica e apolítica, aberta a toda a participação voluntária, vocacionada para os dois objetivos que estão na sua gênese: apoiar a pesquisa científica na região e contribuir para o desenvolvimento endógeno e sustentável das comunidades locais.

A atividade do Centro de Estudos do Deserto incide sobre as populações que habitam áreas desérticas e semidesérticas da província do Namibe, abrangendo no momento o Município do Tombwa, com expectativa de expandir-se para o Município do Virei e do Kuroka (Onkokwa), este na província do Kunene, que no total são habitados por mais de oitenta mil pessoas em situações limite, de subsistência e mesmo de sobrevivência.

Tais situações devem-se aos constrangimentos próprios das regiões áridas, com chuvas que variam entre os $11 \mathrm{~mm}$ e os $100 \mathrm{~mm}$ anuais. A região desperta pouco interesse econômico e, mesmo durante o período colonial, não logrou qualquer programa de desenvolvimento. Isso se deve ao fato de uma parte significativa do território situar-se dentro de reservas e parques naturais, e talvez ao fraco conhecimento que há dessas populações de pastores e de caçadores e recoletores. As condições de vida dessas populações são muito precárias, podendo ser consideradas, em alguns casos, como extremamente pobres. A situação de pobreza verificada torna a vida muito penosa, sendo a maior parte desse peso suportado pelas mulheres e pelas crianças, nomeadamente:

a. na procura da água;

b. no suportar a procriação, a maternidade e o aleitamento;

c. pela incipiente rede escolar e a ausência do ensino profissional, sendo o acesso à escola dificultado pelo carácter transumante do seu modo de vida, pois são as crianças as principais encarregadas de pastar o gado;

d. pela falta de uma rede comercial que compre os produtos da região e venda os bens de uso comum, substituída pelo comércio ad-hoc quase exclusivamente de álcool; 
e. na falta de cuidados médico-sanitários mínimos;

f. pela inexistência de vias de acesso ou existência apenas de trilhos improvisados, em más condições, que dificultam a circulação regular de viaturas, obrigando a caminhadas de muitas dezenas de quilômetros.

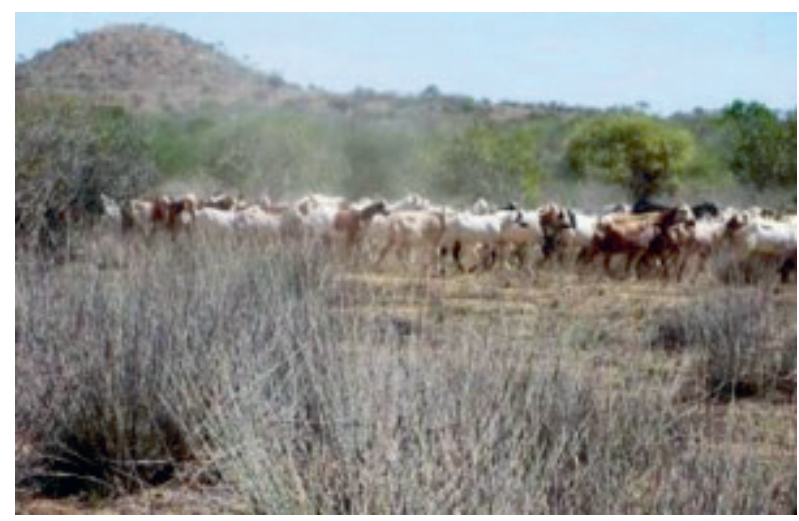

Figura 3.3 - Trânsito de gado no Namibe. Fonte: Acervo CE.DO

O gado bovino, abundante em toda a região, apenas é um valor econômico na medida em que cria algum tipo de estratificação social, hierarquizando os estratos, conferindo diferentes parcelas de poder, consoante à sua posse maior ou menor. Sendo um fator de estruturação social, não é, contudo, um valor comercial como tal. A economia de permuta baseia-se principalmente no gado caprino e ovino, não existindo a monetarização da economia.

A subsistência e os processos de sobrevivência nas condições referidas só são possíveis graças aos conhecimentos profundos que essas comunidades possuem das potencialidades do ecossistema e da forma de como obter dele os recursos mínimos necessários à vida individual e social, em particular, os limites da sustentabilidade que suporta. Qualquer alteração no ecossistema, nas relações sociais ou a interferência externa provoca de imediato desajustes ao nível das pessoas e das suas interações, dificultando o funcionamento dos grupos sociais e, consequentemente, dos elementos que os integram. Dessa forma, o impacto da globalização e o aumento da interferência externa sobre esses modos e práticas de vida, tal como a iminente construção de uma barragem de grandes dimensões no rio Kunene e a estrada necessária à sua construção e funcionamento, põem em risco a preservação da identidade dos grupos, tornando-os indistintos, anódinos e cada vez mais pobres em termos de coesão social e de autoestima, perdendo as suas práticas culturais e a consequente capacidade de agir por vontade própria. 


\section{Atividades do CE.DO: projeto identidade, gênero e desenvolvimento}

No projeto-base de intervenção social do CE.DO, identificam-se ações de realização imediata que podem tornar mais confortável a vida dessas comunidades, mitigando alguns dos grandes constrangimentos que afetam a sua vida cotidiana:

\section{1) Comércio}

Estabelecimento de um sistema de comércio, pela instalação de pontos de venda (cantinas) distribuídos pelo território que adquiram a produção local e abasteçam de bens essenciais as populações ao longo do deserto, quer por troca, quer através da introdução do dinheiro na região.

\section{Subprograma de comercialização e combate à fome, regido por quatro vetores:}

- construção de uma proximidade entre o produto e o consumidor, deixando este de depender para se alimentar do aparecimento esporádico de comerciantes ambulantes ou da deslocação às cidades do Tombwae Namibe (cerca de $200 \mathrm{~km}$ ) garantindo, assim, a oferta imediata de uma maior variedade de produtos;

- busca por um parcelamento das aquisições da produção local (bens trazidos pela população) com dinheiro, introduzido pela primeira vez na região, eliminando gradualmente a troca direta (permuta de gado por mercadoria);

- possibilidade de parcelamento das aquisições pelos consumidores (venda a retalho), pelo recurso ao dinheiro, ao contrário da situação da permuta que só permite aquisições a grosso;

- ampliação das soluções culinárias baseadas nos recursos alimentares habituais, através da divulgação de diferentes formas de alimentação, com vista a enriquecer a dieta das comunidades, atualmente muito restrita e pobre e dependendo das variações sazonais, pela introdução de uma maior diversidade de alimentos que se revelem apetecíveis aos consumidores, após estudo e análise de critérios de consumo. 


\section{Situação atual}

Foi construída a primeira cantina-piloto na região de Ombwhu, a $100 \mathrm{~km}$ do Tombwa, cujo custo orçou em cerca de 1 milhões de Kwanzas; pretende-se instalar outras cantinas assim que existam disponibilidades financeiras.

A cantina encontra-se em funcionamento há cerca de um ano e tem sido importante na mitigação dos efeitos da seca severa que se vive, notando-se a satisfação dos utentes pela sua existência.

\section{2) Saúde}

Criação de dois postos médico-sanitários semi-itinerantes, com capacidade para atender a população, em particular crianças, gestantes e mães, apoiados por duas ambulâncias $4 \times 4$.

\section{3) Formação profissional}

Diversificação das capacidades profissionais da população, em particular das camadas mais jovens e das mulheres, por meio de formações adequadas às características da região, conjugadas com a alfabetização, no Centro de Formação em Artes e Ofícios, construído pelo CE.DO. Concomitante à formação, será incentivada ao longo da região a criação de ateliês e oficinas das diferentes artes e ofícios ministrados no Centro para prestação de serviços e produção de bens de interesse coletivo, como forma de autoemprego.

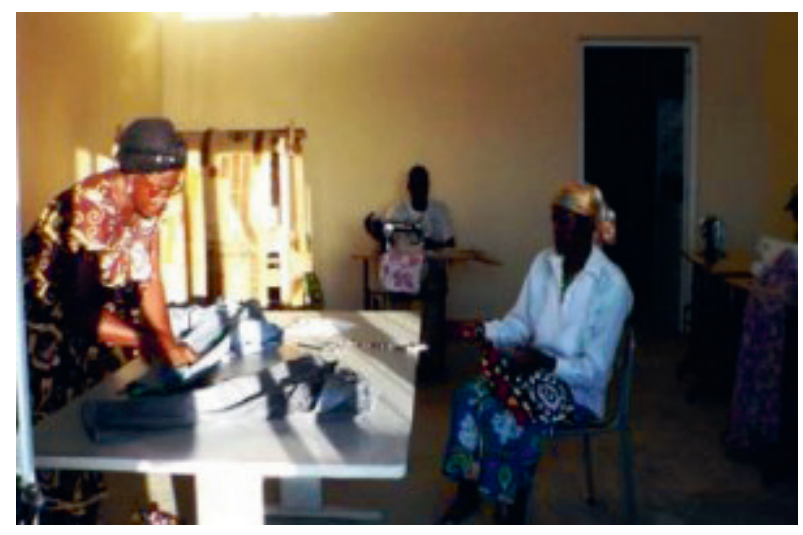

Figura 3.4 - Ateliê de costura do CE.DO. Fonte: acervo CE.DO. 


\section{Sub-programa de construção em terra}

Iniciado em julho de 2009, com a realização do seminário e workshop "Arquitetura em terra - uma aposta para o desenvolvimento de Angola", teve seguimento no primeiro curso de construção em terra, sob o lema "Contribuindo para um habitat melhor" realizado em janeiro deste ano, e visa aos seguintes objetivos:

- promover uma melhor qualidade de vida, no que respeita à habitação, nas aldeias e periferias urbanas, utilizando materiais de baixo custo e de utilização acessível;

- nas zonas rurais, não pretende substituir a habitação tradicional das populações pastoris, conforme às condições ecológicas, econômicas e sociais das suas culturas, mas prevenir o derrube excessivo dos arbustos e mesmo o corte de capim destinado a pastagens, utilizados na construção de certo tipo de habitações:

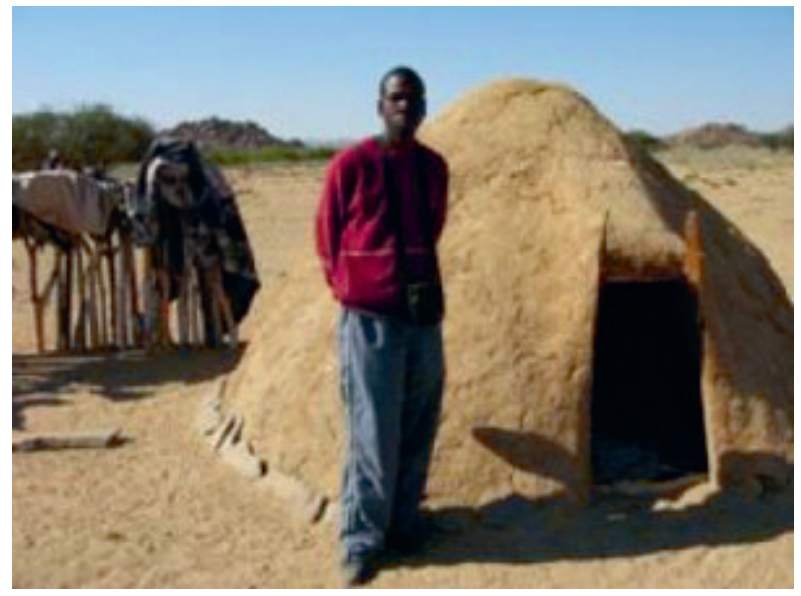

Figura 3.5 - Habitação tradicional, denominada Cubata. Fonte: acervo CE.DO.

- o sistema construtivo utilizado para as construções em terra é econômico: implica baixos custos de transporte, tem um bom comportamento térmico, pode recorrer a mão de obra pouco especializada e permite prazos de execução de obra muito curtos;

- utiliza materiais ecológicos, abundantes na natureza, que não carecem de processos de transformação de matérias-primas que consomem meios energéticos dispendiosos. É reciclável, é reutilizável, é incombustível e não é tóxico. Desse modo, a imputação dos custos de impacto ambiental nesse setor da construção torna essa tecnologia privilegiada entre as outras, 
pelo que o CE.DO opta pela sua divulgação e estudo, como uma premissa do desenvolvimento numa área onde o equilíbrio energético se encontra no limite do viável.

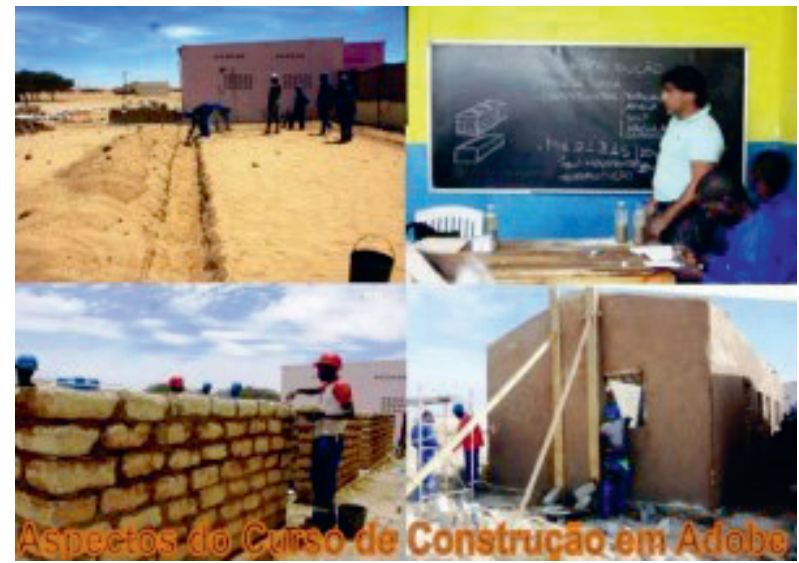

Figura 3.6 - Atividades do CE.DO. Fonte: acervo CE.DO.

\section{Situação atual}

Foi construído o pavilhão para formação em Artes e Ofícios com o patrocínio do governo Provincial e da Toyota de Angola, no valor de USD $380 \mathrm{mil}$; o projeto para realização das atividades de formação obteve o financiamento da Associação do Bloco 15, da operadora ESSO. Por seu turno, o Ministério da Assistência e Reinserção Social disponibilizou equipamento e ferramentas para as várias formações. Igualmente, foi construída uma residência "lar", com cerca de $700 \mathrm{~m}^{2}$, sob administração direta e utilizando o adobe, para acolhimento dos formandos e formadores que venham a participar das formações e que oferece todas as condições de alojamento necessárias. Estão em curso as formações em informática, costura e mecânica, assim como a alfabetização de adultos e o incentivo à leitura (atividades extraescolares) para os alunos da escola local.

Estão identificados os cursos que oferecem interesse à população e que deverão ser realizados em fases, ao longo de três anos: costura, processamento de frutas e legumes, dinamizador rural, artesanato, tecelagem, cerâmica, alfabetização e incentivo à leitura, informática com acesso à internet, mecânico, carpinteiro, guia turístico, pedreiro, serralheiro, bate-chapas, gestão de pequenos negócios. 


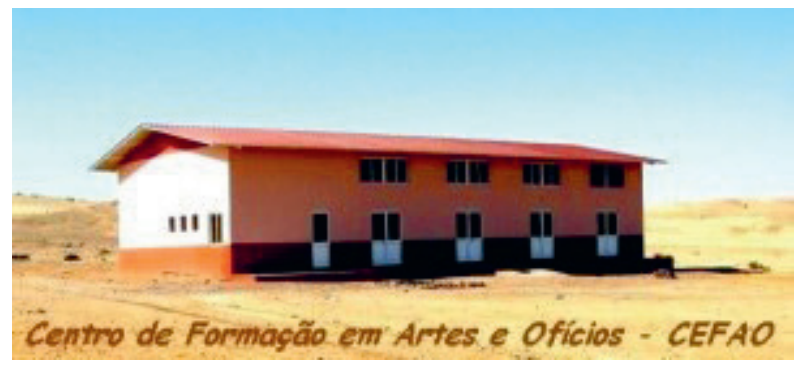

Figura 3.7 - Edifício Centro de Formação Artes e Ofícios. Fonte: acervo CE.DO.

Com o apoio do Projeto Comenius da União Europeia e a participação de doze escolas distribuídas em diferentes países europeus, foi possível angariar fundos que permitiram adquirir uma viatura $4 \times 4$ para recolher as crianças que habitam num perímetro de mais de $10 \mathrm{~km}$ da escola de Njambasana e que, por esse motivo, não podiam frequentar as aulas.

\section{Subprograma de alfabetização e introdução à língua portuguesa}

Criado por exigência expressa pelos moradores da Kamilunga, povoação a cerca de $20 \mathrm{~km}$ de Njambasana e cujas crianças não seriam contempladas pela recolha em viatura pela precariedade da via, visa à criação de pavilhões construídos em material local pelos próprios moradores, assumindo o CE.DO o fornecimento das tábuas para as bancas de escrita e de assento e o pagamento ao monitor local que deve alfabetizar em língua nacional ao mesmo tempo que promove a iniciação à língua portuguesa para que no final do ano as crianças estejam habilitadas a frequentar o ensino regular. Os pais das crianças manifestaram também o desejo de frequentar as aulas.

\section{Situação atual}

Foi construído o primeiro pavilhão escolar na Kamilunga. O monitor foi seminariado na escola de Njambasana, e tiveram início as aulas que decorrem com bom aproveitamento. 


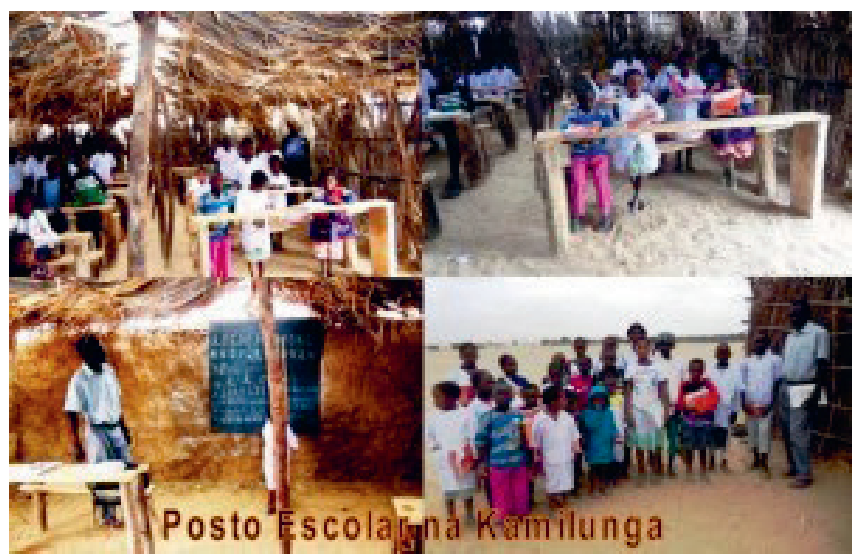

Figura 3.8 - Posto escolar da Kamilunga. Fonte: acervo CE.DO.

\section{4) Água}

Apoiar o programa do governo de abertura de poços artesianos e de instalação de sistemas de bombagem manual ou por painéis solares, sugerindo localizações adequadas e promovendo a melhor utilização pelos utentes, prolongando a vida dos equipamentos.

Avaliação das possibilidades de irrigação para fins agrícolas ou de pastagens. Análise da situação das instalações existentes e que se encontram inoperantes. Distribuição de água a diversos pontos da região, carentes em absoluto desse bem, através de caminhões-cisterna.

\section{Situação atual}

Nenhuma ação realizada até ao momento. Torna-se premente a aquisição de viaturas específicas para essa ação.

\section{Atividade científica}

O CE.DO tem como objeto fundamental contribuir com ações concretas para o estudo das regiões áridas e semiáridas de Angola, nomeadamente o Deserto do Namibe, de modo a aprofundar o conhecimento das suas características físicas, ambientais e sociais, por meio da investigação científica, da educação e ensino, da consultoria e da assessoria técnica, de modo a contribuir para a protecção do ecossistema e para o desenvolvimento sustentável e endógeno dessas regiões. 


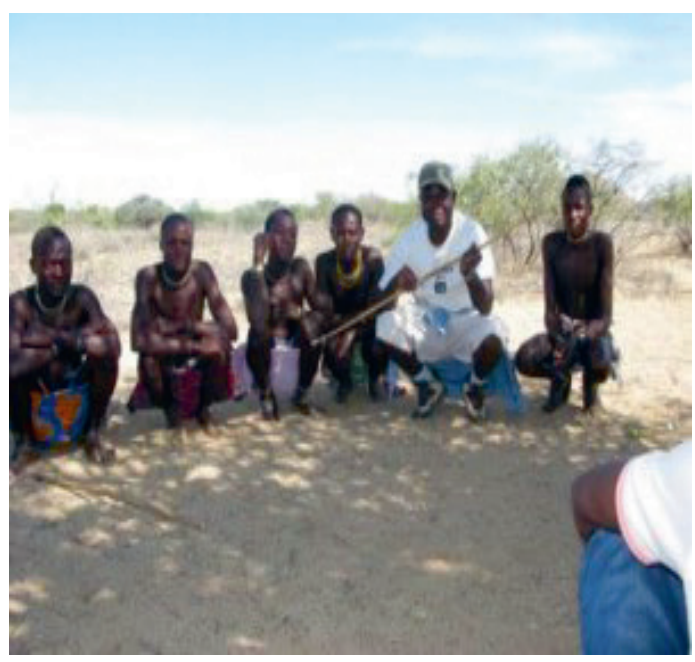

Figura 3.9 - Oficinas. Fonte: acervo CE.DO.

\section{Investigação científica}

O Centro de Estudos do Deserto oferece apoio logístico a investigadores singulares e institucionais que realizem pesquisas sobre a região, em qualquer disciplina científica.

\section{Situação atual}

Até ao momento, participaram em atividades de investigação e visitas de estudo mais de 150 estudantes e sete docentes da Faculdade de Ciências Sociais da Universidade Agostinho Neto; os seus interesses de pesquisa incidem sobre as comunidades pré-Bantu, Kwepe, Kwisi e Kwambundu e ainda sobre os grupos Kimbarie Herero. Igualmente, desenvolvem-se pesquisas sobre os comerciantes do deserto e a transumância cíclica do gado.

O CE.DO tem protocolos assinados com o Instituto de Ciências Sociais da Universidade de Lisboa (ICS/UL), com o qual desenvolveu a pesquisa sobre "o capital social da região", com o Centro de Estudos Africanos do Instituto Superior de Ciências do Trabalho e da Empresa - Instituto Universitário (ISCTE-IUL) de Lisboa e o Centro de Investigação em Biodiversidade e Recursos Genéticos da Universidade do Porto (CIBIO-InBIO/UP). Registaram-se visitas de trabalho de duas investigadoras portuguesas e de um investigador espanhol.

O CE.DO garantiu ainda a hospedagem e acompanhamento local, durante três meses, a uma estudante de mestrado da Universidade Federal de Santa Cata- 
rina, Brasil, e recebeu a visita de dois professores da mesma universidade. Apoiou em dois anos consecutivos, por períodos de um mês, a pesquisa sobre o capital genético das comunidades pré-Bantu numa geminação do Centro de Biologia da Universidade do Porto (CIBIOInBIO) com o Instituto Superior de Ciências da Educação (ISCED) do Lubango. Durante essa pesquisa, foi identificada uma senhora conhecedora da antiga língua Kwepe, o Kwadi, considerada extinta, pelo que foi possível organizar uma pesquisa com a participação do Instituto Max-Planck de Antropologia Evolutiva da Alemanha. Esta senhora colaborou com a Companhia de Dança Contemporânea (CDC) na recolha de elementos cenográficos e sonoros para a realização da peça Paisagens Propícias, sobre o sudoeste de Angola e o trabalho do antropólogo Ruy Duarte de Carvalho.

\section{Seminários do Centro de Estudos do Deserto}

Prevê-se a realização de encontros sob a forma de seminário com frequência mensal na nossa sede em Njambasana ou nas cidades vizinhas, tendo como objetivo reunir de forma regular estudantes do ensino superior e médio e investigadores e outros estudiosos em questões relacionadas com o contexto das regiões áridas - desérticas e semidesérticas -, em particular do deserto do Namibe, assim como outros temas de relevância para a juventude. Esses encontros visam à reprodução do conhecimento, pois deverão ser replicados nas escolas de proveniência dos estudantes por aqueles que os frequentaram. Pretende-se, assim, criar núcleos de estudos sobre diferentes matérias de interesse acadêmico e social.

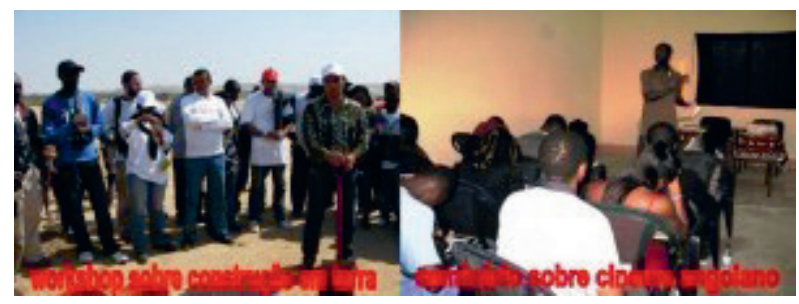

Figura 3.10 - Atividades do CE.DO. Fonte: Acervo CE.DO.

\section{Situação atual}

Até o presente, realizaram-se dois seminários e um workshop: A arquitectura em terra, uma aposta para o desenvolvimento de Angola, A relevância dos estudos antropológicos em Angola e Mostra e debate sobre o cinema angolano, com participações excelentes em termos de presenças e intervenções. 


\section{Observatório da Transumância}

O CE.DO tem em curso a implantação na região de um observatório que, de um modo sistemático, deve efetuar o registo dos fenômenos migratórios de pessoas e gado em transumância e estudar todos os aspectos a eles associados. Será um contributo não só para a compreensão desse tão importante fato social como para a procura de vias de permanência e transformação em condições de mudança social.

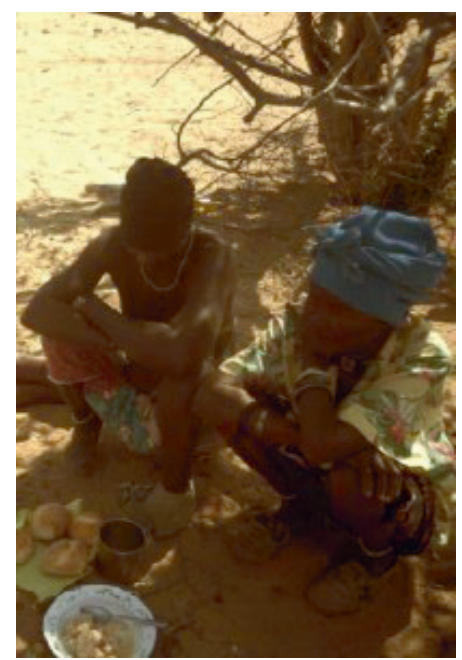

Figura 3.11 - Alimentação dos pastores. Fonte: Acervo CE.DO

\section{Situação atual}

Essa pesquisa será associada à Universidade Federal de Santa Catarina, Brasil, por meio do projeto Kadila, e devem ainda ser solicitados apoios aos Governos Provinciais do Namibe, Kunene e Huíla, assim como aos Ministérios da Cultura, Ambiente, Agricultura, Desenvolvimento Rural e da Administração do Território. 
